Ibrahima Amadou Dia

\title{
African languages, and information communication technologies and development
}

\begin{abstract}
This study aims to comprehend the intersections between African languages and information communication technologies (ICTs) and African development and the ensuing opportunities and gaps. First, it presents the theoretical model underpinning this article. Second, it analyzes some initiatives aimed at addressing social and economic hardships whilst strengthening the African indigenous languages. Third, it points out the shortcomings in using ICTs devices to mainstream the African languages into development programs. In conclusion, we argue that the African languages and the ICTs should be in the heart of development policies in Africa.
\end{abstract}

Keywords: African languages, ICTs, language capital, development, poverty reduction, indocility

Ibrahima Amadou Dia: University of Geneva. E-mail: Ibrahima.Dia@unige.ch

\section{Introduction}

The potential of the African indigenous languages to catalyze sustainable development has for long been overlooked by national and international stakeholders. In addition, projects and programs pertaining to African language promotion in cyberspace have been hindered by infrastructural, financial and socio-cultural constraints and a lack of political commitment. Nevertheless, there is a burgeoning awareness among researchers, governments and international agencies of the developmental potential that can emerge from the intersection between ICTs and the indigenous languages. The fascination towards the ICTs should not preclude a critical assessment of the rationales and logics underlying its application in developing countries. The fact that the ICTs have development potential is beyond dispute. However, it is important to examine their advantages and drawbacks, which is one of the main objectives of this article.

This article endeavors to show the way that African indigenous languages and ICTs are mainstreamed into sectoral development programs. To do so, it 
draws on selected initiatives relating to education, gender equality, poverty reduction, democracy and good governance and migration and development. First, it provides some insights on the theoretical and methodological approach and then reflects on the opportunities and shortcomings of some of the ICTs applications before pointing to the need to consider the ICTs in the African context beyond fascination and pessimism. The conclusion argues that strengthening grassroots strategies aimed to mainstream the African languages and ICTs into development requires effective involvement of the national stakeholders.

\section{A brief overview of the theoretical and methodological approach}

This study accents the concepts of language capital and linguistic capital (Bourdieu and Wacquant 1992; Bourdieu 1977: 651-653). Bourdieu's language capital will be complemented by the paradigm of indocility evidenced in contemporary African scholarship (e.g. Ela 1998; Mbembe 1992). In his attempt to adapt Bourdieu's model to the complex Sub-Saharan African multilingual context, Omoniyi (2003: 7) argued for differentiating linguistic capital and language capital, the former pertaining to "intra-language competition" (2003: 7) and the latter relating to the multilingual situations. At a theoretical level, the notion of language capital can be critical in theorizing the intersections between African languages, ICTs and development in Sub-Saharan Africa. The question of linguistic capital and language capital and their implications for access to ICTs should be understood in relation to the former colonial languages but also the localized African languages. Various applications of ICTs could hold significant results but one of the main challenges remains the language and technical barriers. This shows that the possession or not of linguistic capital is crucial to determine the access to ICTs in particular the internet.

Development is an ambivalent concept, reflecting conflicting perspectives. Edelman and Haugerud (2004: 1-2) point to the way the concept of development is conflated with economic globalization and the differing usage of such a concept. It is used as "discourse, as policy or project blueprint, as historical process, or as self-propelled evolutionary process” (Edelman and Haugerud 2004: 2).

Conventional definitions articulate the notion of development to improvement in the living conditions, quality of life and to the "historical processes of commodification, industrialization, modernization, or globalization" (Edelman and Haugerud 2004: 2). However, the economist' conception of development was criticized for its narrow focus on economic growth (UNDP 1990; Sen 1999). 
Although economic growth is seen as instrumental, development should be considered as process underlying societal transformations and the whole society. To address the pitfalls underlying the economist' conception of development, some scholars such as Sen and some international agencies like the UNDP (United Nations Development Programme) have set up human development indicators (Szirmai 2005: 7).

The narrow focus on economic growth and macroeconomic welfare has led to a sociolinguistic and development model valuing the European languages and discarding the African indigenous ones. Binaries such as the formal and the informal economy have been replicated in the linguistic market with the prominence of the European languages and the marginalization of the African indigenous languages. Development policymakers tend to ignore the fact that the informal economy in Sub-Saharan Africa, which represents a large share of the national GDP and concentrates the majority of the active population operates mainly through the African indigenous languages. Thus, any marginalization of the indigenous languages can inhibit the potential of the informal economy to impact on national development (Djité 2008).

ICTs can be defined as networks or nodes of technological innovations composed by computing, microelectronics, electronic communication (including broadcasting and the internet). ${ }^{1}$ ICTs have shifted the processes of information and knowledge production, dissemination and reproduction, leading to time compression and facilities in terms of interactivity (Norris 2001). ICTs can be used for purposes like political and social mobilization (Norris 2001) and strengthening citizenship during presidential elections (Dia 2001). While the internet has reinforced the prominence of English as an international language, it can offer possibilities to promote multilingualism and multiculturalism.

African indigenous languages or African local languages are defined in this study as languages originating in the African continent while former colonial languages, Western languages or European languages refer to languages of European origin (e.g. Prah 2010). This does not involve a willingness to discard the differences within the European languages, the differing colonization styles (e.g. Mufwene 2002) and the linguistic hybridizations in African societies (e.g. Nkolola 2010).

This study is based on a literature review with a focus on selected SubSaharan African countries as case studies and selected thematic areas. These choices were based on the availability of the literature rather than reflecting

1 World Bank ICT at a glance definitions and sources: http://econ.worldbank.org/WBSITE/ EXTERNAL/DATASTATISTICS/0, contentMDK:20460697 isCURL:Y menuPK:1192714 pagePK: 64133150 piPK:64133175 theSitePK:239419,00.html (accessed 13 November 2010). 
an intention to leave out other Millennium Development Goals or development issues like maternal health, environmental sustainability, to list a few. The lack of assessment studies regarding the impact of the ICTs on African languages and African development constitutes a limitation to this study. To offset this constraint, various sources of information were consulted to gain more insights on the selected themes. Though, this article does not pretend to provide depth understanding of the trends and challenges involved. In what follows, we analyze the intersection between the African languages, ICTs and sectoral development programs through a thematic perspective focusing in each case on the ensuing opportunities and shortcomings.

\section{African languages, ICTs and education}

Wide ranging programs on ICTs and indigenous languages in education have been carried out by state and non state actors. Instances of activities pertaining to online education in Africa using the indigenous languages are provided below.

The ANAFA² project, also called Alf@net, was set up in 1997 and encompasses literacy activities intended for Senegalese and Malian women and the localization of the national languages (Wolof and Bambara). Drawing on the achievement of the first phase, the ANAFA has launched an Alf@net research action and an initiative called Batik program under the triennial program (2000-2004), aimed at promoting female literacy and traditional dyeing activities through an integrative approach. The success of the Alf@net program is due to its integrative approach that combines language literacy, localization of the national languages and training the local population on the use of ICT devices. ${ }^{3}$

The African Language Materials Archive (2010), a joint project partnering the West African Research Association, Columbia University and the Digital Library of International Research, relate to supporting the access to scholarly publications in African languages (Fulfulde, Bamanankan, Songhay, Bamanan and Wolof) dealing with topics such as human rights, HIV prevention, religious texts, entrepreneurship and folktales. This project involves also a CD-Rom edition containing a navigation menu in English, French, Fulfulde, Mandingo and Wolof. ${ }^{4}$

2 See ANAFA Projet Alf@net Les TIC en langues nationales : http://www.alfanet.anafa.org/ (accessed 20 August 2010).

3 Alf@net Site Internet du programme Alf@net http://www.alfanet.anafa.org/ (accessed 20 August 2010).

4 African Language Materials Archive: http://alma.matrix.msu.edu/ (accessed 20 August 2010). 
The United Nations Economic Commission of Africa (UNECA) has supported projects pertaining to Open Source Software (the AAU VaristyNet project) in Ethiopia and content generation in local languages (the Rural Electronic Schools in African Languages, or ERELA project) in Cameroon. The AAU VaristyNet project is said to have helped simplify the Ethiopic characters for its online script recognition. The ERELA project involves the construction of two pilot primary schools, the development of training manuals on local languages and equipment on software on computers (UNECA 2007: 12-13). Frequent electricity cuts offs were reported as a main challenge in implementing the initial phase of the ELERA project. ${ }^{5}$

The African Academy of Languages (ACALAN) ${ }^{6}$ is active in supporting scientific and technical cooperation among the African countries on African languages. In 2006, the ACALAN has carried out a project on African languages and cyberspaces aimed at promoting the use of African languages in education, in partnership with the Meraka Institute (South Africa) and PANOS West Africa.

The above-mentioned initiatives are intended to strengthen the use of the African indigenous languages in education and literacy programs. However, they may hold limited results due to various constraints including the low number of scholarly publications in African languages, the difficulties relating to the localization of African languages, the prominence of European languages and the high rate of illiteracy despite of wide ranging programs.

On one hand, there are a tiny number of scientific documents available in African languages in cyberspace in contrast to the extensive literature on African languages produced in European languages. On the other, the relatively high number of illiterate people prevents many in having access to these scientific publications. Training manuals on content generation in local languages and toolkits for creating and editing websites are quite generally in English or other European languages and imply programmers and local language trainers to be literate in these languages. African languages seem to be more a research topic or point to debate than a broad communication medium in the cyberspace. Many websites in African languages have their audience outside the African continent. Another constraint points to the reluctance of foreign sponsors to invest in ICTs and African languages (Osborn 2006: 87-89).

5 Cameroon: R\&D Computational Linguistic: National application of ARN Local Language Research Studies recommendations: http://www.google.ca/url?sa=t\&rct=j\&q=\&esrc=s\&frm= $1 \&$ source=web\&cd=1\&ved=0CCsQFjAA\&url=http $\% 3 \mathrm{~A} \% 2 \mathrm{~F} \% 2$ Faaf.afrinic.net $\% 2$ FCurrent $\% 2520$ Research\%2520activities\%2520summaries.doc\&ei=zKF_Ut_ZEsmRtQa24YGYCA\&usg= AFQjCNFAOGRjOWYYgsWZQgCH3x1u9bHliw\&bvm=bv.56146854,d.Yms (accessed 11 November 2010). 6 Académie des Langues Africaines http://www.acalan.org/eng/accueil/accueil.php (accessed 20 August 2010). 
Notwithstanding the initiatives related to the localization of African languages, few have online content generation on education and literacy. Only a small number of local African languages have online resources (UNECA 2007: 13). These languages include Akan, Igbo, Fulani, Hausa, Luganda, Mandingo, Masai, Ndebele, Sesotho, Shona, Swahili, Xhosa, Yoruba and Wolof. A study of the level of presence of 64 African languages in cyberspace points to the prominence of the number of websites in European languages devoted to research and documentation on African languages. Websites in English and French pertaining to African languages account to $80 \%$ and $8 \%$, respectively. In contrast, the number of websites in African languages was found to be low, representing 3\%. There are few people who use their African mother tongue in online communication. The situation in print media reflects also a marginalization of African indigenous languages (Diki-Kidiri 2004: 46-48).

In exploring the use of ICT for curriculum planning and educational development in Uganda, Mutonyi and Norton (2007: 264-270) identified the following challenges: the lack of empirical data on ICT connectivity and use; the differing situation between urban and rural communities and male and female students; the importance of training the teachers for curriculum development and the need to combine both in- and out-of-school digital literary practices and the importance to adapt global software to local needs.

Now, we turn to how African languages have intersected with ICTs in projects pertaining to gender equality.

\section{African languages, ICTs and gender equality}

In South Africa, some initiatives set up by civil society associations and companies to facilitate the access of women to low-cost ICTs endeavor simultaneously to strengthen the capacities of women's organizations and to address issues such as HIV/AIDS prevention and violence against women and children. South African rural women targeted in these projects were trained so that they can report gender-based violence via text messaging and radio programs and use the internet to search for artisan information and marketing products. The use of mobile telephone, land line and other ICTs devices by South African rural women for social and economic purposes is said to have contributed to their empowerment. However, in spite of the enthusiasm of South African rural women in participating in learning programs on online communication and searching through the internet, illiteracy and language barrier were identified as major hindrances to the use of ICTs devices designed to promote gender equality, livelihoods and education in rural South Africa (Joseph and Andrew 2007: 5-15). 
Assessment of an ACACIA project in Senegal relating to the use of ICTs for awareness-raising on gender equality reveals a greater awareness of the Senegalese national stakeholders on joint parenting issues. However, low connectivity, limited number of people with email addresses, financial constraints and high rate of illiteracy in French were found to hinder the potential in using the internet to sensitize the local and national officials. There is an elitist utilization of the internet due to the accessibility problems faced by the majority of the local populations. In contrast, awareness-raising programs on gender equality via classic radio programs were found to yield more convincing results than those based on modern technologies such as internet (Sene and Thioune 2003: 38).

Language barriers constitute a major problem for the adoption of ICTs by African women organizations working on gender equality and women empowerment. The problem of language barriers was emphasized by some African women's organizations during the Sixth African Regional Conference on Women held in Addis Ababa, Ethiopia, 22-27 November 1999 (APC-Africa-Women "From Beijing to Beijing +5", quoted by Adeya [2001: 13 and 25]).

Thus, what stands out is that initiatives aimed at using the ICTs to promote gender equality are hindered among other obstacles by accessibility problems associated with high illiteracy of the local population in European languages, and their lack of computer skills.

\section{African languages, ICTs and poverty reduction}

The UNECA has supported research and development activities initiated by VarsityNet to promote the local African languages in health and commerce information system in Ethiopia. The AAU VarsityNet project within the framework of UNECA's VarsityNet program endeavors to generate information system applied to health and commerce using mobile telephone technology. This project has supported the creation of a prototype allowing medical practitioners to have access to patient's records and to enter clinical data using the same mobile telephones (UNECA 2007: 12-13).

The Technical Centre for Agricultural and Rural Co-operation (CTA) has launched an initiative called "Hallo Engineer" that enables rural farmers in West Africa to use mobile phones to ask an agricultural expert or engineer questions related to agriculture. Such "question and answer service" scheme is free of charge as the farmer beeps and flashes the agricultural expert who in turn calls back to provide information needed in the rural farmer's local language. Cameroon was the regional focal point for this project with the neighboring countries 
benefiting from it. An extension phase of the "Hallo Engineer" was planned with the inclusion of other Southern African languages (Munyua 2007: 43).

Between 2001 and 2006, in Niger, an initiative to provide inexpensive search technology to grain traders and other market actors has contributed to lower grain price dispersion to a minimum 6.4 percent (Aker 2008). In 2008, the International Food Policy Research Institute supported the establishment of the Ethiopia Commodity Exchange, an institution that caters for new ICTs market information and trading systems to help link buyers and sellers (von Braum 2010: 9).

Fishermen in Senegal use largely mobile phones for their daily activities, as evidenced in a study of fishermen in Guet-Ndar, Kayar and Mbour (main Senegalese fishery centers) and their adoption of ICTs. Most view modern technology devices as instrumental, allowing them to have access to meteorological information in local languages through the SMS technology or to maximize stock or reduce the likelihood of occupational hazards while at sea by using mobile phones and GPS (Sall 2009: 101).

Whereas mobile phones are used widely in daily life including for economic purposes, the adoption of mobile internet by the local population in Africa seems to be low. A study on the role of mobile internet in addressing social exclusion (Chigona et al. 2009: 9) indicates that though mobile internet may facilitate social inclusion its impact in economic and political terms are low. However, the lack of content generation in local African languages plus high costs and technical problems (lack of functionalities and problems of speediness) impede the potential of mobile internet technologies vis-à-vis poverty reduction and social inclusion.

There are various challenges in using ICTs to promote agriculture, rural development and poverty reduction, as emphasized in a study of the use of ICTs by small farmers in Zambia. These constraints are several and include the following:

a. high costs of the telecommunication services and internet access,

b. duplicating the efforts of different ministries and other national stakeholders,

c. lack of an integrated approach in establishing information gateways,

d. weak commitment on the part of government in developing strategies for combating ICTs, legal, financial and infrastructural obstacles,

e. lack of a coordinated framework for national information communication (Kalusopa 2005: 422).

In addition, difficulties of access to the relevant information due to language barriers and the lack of content adapted to the local needs and cultures may hinder the use of the ICTs by rural farmers in their daily livelihood strategies. According to Munya (2007: 30), "[m]ost content available on the web is too technical for farmers and it is largely in English”. In Senegal, while grassroots organizations recognize the speed of the internet in comparison with other communication de- 
vices like mailing post, which can facilitate capacity building and social networking, they express concerns about expensive costs related to internet services and frequent blacks out (Agboli 2008: 22-24).

Drawing on the above-mentioned examples, one can assume that ICTs can play a significant role in Sub-Saharan Africa, but their application to enhance the agricultural and farming system, to promote social development and fight against poverty “. . . may fail simply because conditioning factors such as literacy, service providers, and language or content issues have not been addressed” (Maumbe and Okello 2010: 15).

\section{African languages, ICTs, democracy and good governance}

The intersection of ICTs and African indigenous languages were identified as one of the enabling factors of the political transitions observed in some Sub-Saharan African countries in the past years (Sagna 2001; Dia 2001; Coulibaly 2001: 1-8). Thanks to private radio and mobile phone technology, there has been a "supervision populaire” (Sagna 2001: 39) ('popular control' - my translation) of the overall electoral processes, as evidenced in the 2000 Senegalese presidential election (Sagna 2001). While private and popular radios and mobile phones may impact positively on the electoral process, this should not paper over the pitfalls in employing ICTs to promote democracy and good governance in Sub-Saharan African countries. Projects related to e-governance in those countries are unlikely to succeed fully due to language barriers. For instance, the Ghana governmental website is only available in English, whereas 70\% of the local populations refer to the Ghanaian local languages in their daily lives (Schuppan 2009: 123).

Language barriers also impede the employment of ICTs to strengthen activities and programs related to local decentralization. An ACACIA project aims to use ICT resources to address the technical and language (illiteracy problems in French) barrier problems faced by the local elected officials in understanding the legal and legislative texts related to decentralization policy in Senegal with limited success. While the project was welcomed by national and local stakeholders, there was no evidence as to whether it has impacted decentralization policies. The project revolved around capacity building, publication and dissemination of official texts on decentralization policy in Senegal including online posting and sensitization programs in Senegalese national languages. However, there was no indication whether the products of the project were used widely by the local officials. In spite of efforts to translate laws and legislations into local languages, the 
fact that these official texts were mainly available in French still prevents many local elected officials from accessing relevant information (Sene and Thioune 2003: 41-44).

In addition to the use of the internet during national elections (e-governance), the internet is increasingly used by dissident political groups to protest against government policy in Sub-Saharan African countries (e.g. Wasserman and de Beer 2004).

\section{African languages, ICTs, migration and development}

ICTs in general and mobile phones and the internet in particular, have a fundamental communicational component for emigrants and their families. There are various modes of usage of ICTs by emigrants including mobile phones, land lines, fax, radios, video, email exchanges, skype, facebook, online forums, online dating and storages. African migrants use ICTs devices to create and strengthen links with the homeland or to display multiple belongings ${ }^{7}$ (e.g. Dia 2009; Tynes 2007).

There are many websites and blogs created by African immigrants especially in Europe and North America that offer a range of possibilities: access to online news publishing (Ndangam 2008), online discussions, online radio, access to audio and video types elements (including local and national radios and televisions). Increasingly, dissident political groups including the African Diaspora communities are using the Internet to protest against bad governance and corruption in Africa. These websites created by activist African migrants and also by autochthons have altered the reality of the online African information market which was controlled by international actors operating quite generally in European languages (Guignard 2008: 319-325). In content analyzing selected websites $^{8}$ that are created fully or in part by Africans abroad, we found that they were mainly focused on news (especially politics), religion, entertainment and edutainment, online discussions and training materials on African languages. These findings are consistent with research carried out by Van der Veken and de Schryver about the presence of Somali, Lingala and Isixhosa in the Web.

7 International migration and diasporization may also involve disruption of linguistic ties due to the lack of intergenerational transmission of the indigenous languages in migrant families.

8 The websites content analyzed are: www.peeral.com (in Fulani) (accessed 6 September 2010) (Barry 2010) and http://www.wolof-online.com/ (in Wolof). 
Some argue that beyond the objectives of preserving homeland culture, language and identity, these websites tend to be business oriented (Guignard 2008: 312-316). However, this should not leave out the fact that migrants are engaged in local and national development in various ways. Through these online practices, they can contribute to increase the international visibility of their mother tongue and locality of origin and channel transnational or translocal networks to support the homeland development. They may also use ICTs to initiate philanthropic and fundraising activities to address social and economic needs such as building health centers and improving literacy including in the African indigenous languages.

Skilled or highly skilled migrants are more inclined to use the internet allowing more possibilities beyond mere access to local media unlike low and unskilled migrants who tend to rely more on local radio (via Worldspace) and television programs (Guignard 2008: 312-317) due to illiteracy problems in European languages and lack of computer skills. This reflects an elitist use of internet and a digital gap even during the course of international migration. In the following section, I will reflect on some of the constraints that may hinder the use of the ICTs in strengthening the role of African languages in sustainable development in Sub-Saharan Africa.

\section{Mainstreaming African languages and ICTs into development programs: beyond fascination and pessimism}

Although the ICTs are dominated by European languages, there are possible avenues to promote African indigenous languages in cyberspaces. However, many questions need further understanding. These include whether the development model underpinning ICTs is effective for the preservation and the strengthening of African languages. There is a need to assess ICTs applications in Sub-Saharan Africa beyond fascination ${ }^{9}$ and pessimism. Such assessment could help address the knowledge gaps relating to the initiatives aimed at mainstreaming African indigenous languages and ICTs into development programs, the ensuing opportunities and shortcomings and the lessons learned. In what follows, I provide

9 For instance, Senegalese newspapers have commented on the adoption of the Wap (Wireless Application Protocol) by some rural farmers as a "revolution". Only few of them were sceptical about the real outcomes in using the information communication technologies (for example mobile internet) to improve the rural livelihood (Guignard 2008: 289). 
some insights on the challenges ahead and suggest possible ways to reinforce the role of the African languages on ICTs and development projects.

The international digital divide between information haves and have-nots is well documented (see for instance Warschauer [2004]). In addition to the divide between countries, there is "a gradation based on different degrees of access to information technology" (Warschauer 2004: 6). The digital divide between the developed and developing worlds is exemplified among other elements in the uneven global distribution of computers telephone and internet connectivity, and information flow, and high illiteracy. This divide stems from a range of factors including poverty, weak infrastructural system exemplified by lack of electricity, slow progress in the bid to raise literacy rates, and connectivity. A digital divide ${ }^{10}$ within developing countries also exists, with higher connectivity in big cities in contrast to rural areas where the use of the local languages is more widespread (Osborn 2006: 86).

One of the main challenges of ICT projects is that they "too often focus on providing hardware and software and pay sufficient attention to the human and social systems that must also change for technology to make a difference" (Warschauer 2004: 6). Thus, the contextual factors surrounding the use of ICTs should be taken into account.

Lallana and Uy (2003: 32-33) identified four types of content problems that limit access to the internet: obstacles to the access of local information, literacy problems, language barriers and obstacles related to cultural diversity. Regarding the problem of access to local information, commercial content providers may be less motivated to create local content if the profit margin is low. Consequently, it may be difficult for users in developing countries to find information adapted to their local needs. In addition, sustainability of ICT related initiatives sponsored by NGOs and non-profit organizations may be difficult due to insufficient funding as well as short term orientation. The literacy problems relate both to basic and functional literacy difficulties. The latter includes technological and language barrier problems in surfing through the internet for information. To alleviate these problems and reduce the digital divide, Lallana and Uy (2003: 33) suggest the adoption of voice recognition technologies which will involve less onerous literacy skills.

10 According to Powell (2001: 252), echoing Amadou Top, President of the Observatoire sur les Systemes d'Information les Reseaux et les Inforoutes au Senegal (OSIRIS), there is a widening digital divide in Sub-Saharan African countries but the existence of a culture of sharing consumer goods that extends to "telephones and to the internet" may lower - though to a lesser extent - the volume and magnitude of the digital divide in these countries. 
In the same vein, Maumbe and Okello (2010: 9) point out the constraints below: language barriers (lack of content generation in local languages), limited connectivity, expensive tariff rates, telecommunication sector crisis, infrastructural gaps, frequent electricity power cuts and discrepancies in the markets and services.

The digital divide should not be separated from the other forms of marginalization and challenges hampering many Sub-Saharan African countries. While an optimistic analysis may see ICTs as catalysts for economic growth and social welfare, most authors are pessimistic about the role of ICTs in developing countries, pointing to their limited outcomes due to persisting digital divide and constraining structural conditions (von Braun 2010: 9; Dia 2001). ICTs are viewed by pessimist discourse as a manifestation of the ideology of catch-up and as a form of reproduction of Western hegemony and its mercantilist logic (Dia 2001, 2009).

Thus, an understanding of ICTs and their links with African languages and sustainable development cannot be dissociated from an examination of past and contemporary development policies in order to avoid replicating old fallacies and gaps. The failure or the success of the application of ICTs in sectoral development programs would depend on various factors, including how the African states tackle the obstacles hindering the development process. As long as political, institutional, economic, linguistic and cultural factors are overlooked in the context of "ICTs and development" (own emphasis), the digital divide is likely to worsen the linguistic divide in cyberspace, with the prominence of the European languages.

The rationale behind the idea of ICTs for development is that information is essential for development planning and policy (Harris 2004: 15). Thus, making ICTs accessible to the ordinary people by providing them with the appropriate support (for instance, ICTs training and knowledge information in local languages and access to affordable equipment) and creating income-generating activities linked directly or indirectly to these modern technologies can help improve their livelihoods whilst reducing, to some extent, the digital divide. Though, this implies an integrative approach that singles out African local languages and cultures as vital (rather than peripheral) resources as far as strengthening the capacities of local communities and securing their livelihoods.

While mobile phones and private and community radios have expanded over the last few decades, this is not the case for the internet, which is out of reach for millions of Africans due to the above-mentioned challenges. Mobile phones are used by many ordinary people in their daily life because beyond the affordable costs, there is lesser language, technical and infrastructural constraints unlike in the case of the internet where accessibility problems are frequent, which may explain their adaptation to the African multilingual context. The usage of mobile 
phones does not require full proficiency in European languages. If used for more than social cohesion and solidarity (communicational social links) - which is crucial - mobile phones can catalyze knowledge for local development. This can enrich the linguistic and cultural diversity and enable more interactions between the development agents and agencies (engineers, experts, local and national stakeholders, NGOs, for example) and the local African population, as evidenced in the "Hallo Engineer" project.

According to Cechinni and Scott (2003), in order to maximize the potentials of ICTs for poverty reduction and sustainable development, the question of ownership should be addressed. Most people in developing countries especially in the rural areas who lack computer skills rely on a "human intermediary between them and ICT" (Cechinni and Scott 2003: 80), called also "reintermediation model" (2003: 80) to use the internet device. The intermediaries (for instance, telekiosks operators) can facilitate reaching impoverished people in the rural zones in the context of ICT for poverty reduction projects. Omoniyi (2007) sites the use of IT-resourced information kiosks by Pride Africa, an NGO, to boost agricultural production among rural farmers in northern Kenya. Telekiosks' operators have computer skills, and, in addition, they are proficient in local languages and understand the specificities, cultures and needs of the rural populations, which can be assets for the ICTs poverty reduction projects, as evidenced in some rural areas in India. Thus, it is important to strengthen the capacities of these social actors who work at the grassroots level as the success of projects pertaining to empowerment of rural communities may depend among other factors on their enthusiasm, competences and dexterities (Cechinni and Scott 2003: 80).

Scale-up projects can lead to greater sustainability of projects related to African languages, ICTs and development, while strengthening existing successful initiatives. Extensive researches should be carried out to help better mainstreaming African languages into ICTs for development projects while assessing the strengths and shortcomings of the existing initiatives (Rashid and Elder 2009: 12-13).

\section{Conclusion}

The success or failure of the application of the ICTs in education, agriculture, poverty reduction, gender equality and local development will depend on how the Sub-Saharan African countries address the development challenges and the constraints hindering the expansion of the ICTs in Sub-Saharan Africa (Maumbe and Okello 2010: 9). The ICTs are customized at the grassroots level to respond to 
social needs and emergencies and to create and maintain social relationships (Rashid and Elder 2009: 12-13; Warschauer 2001, 2004).

However, the obstacles to achieving the MDGs cannot be removed simply by the adoption of the ICTs by local populations. Fascination with these modern technology devices may lead to illusions and shortcomings due to an underestimation of the development challenges and the constraining structural conditions that may inhibit their potential benefits. As stated by Warschauer (2004) and Snyder and Prinsloo (2007), ICTs should not be considered as a panacea to address the longing economic crisis, poverty and other challenges facing most developing countries. Local, national and international stakeholders should work in close conjunction to work out appropriate policies to respond to the digital gaps while considering the linguistic and developmental implications of ICT projects and programs for the local communities. The digital divide not only concerns the disparities between the developing and the developed regions. There is also a digital divide within the developing countries (between the rural and urban areas and among the social groups). Thus, special emphasis should be placed on training the local population in using ICTs. These training programs should be linked with income-generating activities, local language promotion and awareness raising programs (for instance, health prevention, gender equality and environment) in African indigenous languages.

The processes of indigenization of ICTs from below (by the local populations) show that the ongoing social, political and economic reconfigurations in SubSaharan African countries occur more often outside the official or the state scheme. In the absence of effective policies aimed at regulating the ICTs, many ordinary people attempt to take control of these technology devices and adapt them to their daily lives. These forms of renaissance from below represent an assault against failed state policies or the lack of state. Thus, one could question the role of the African States under the conditions of globalization (Dia 2001).

\section{References}

Académie des Langues Africaines (ACALAN). 2010. http://www.acalan.org/eng/accueil/ accueil.php (accessed 24 August 2010).

Adeya, Catherine Nyaki. 2001. Information and communication technologies in Africa: A review and selective annotated bibliography 1990-2000. Oxford, UK: International Network for the Availability of Scientific Publications (INASP).

African Language Materials Archive. 2010. http://alma.matrix.msu.edu/ (accessed 6 September 2010).

Agbobli, C. 2008. Internet and development in Senegal: towards new forms of use. Africa Media Review 16(2). 11-28. 
Aker, Jenny C. 2008. Does digital divide or provide? The impact of cell phones on grain markets in Niger. BREAD working paper. Harvard University: Center for International Development.

ANAFA Projet Alf@net. 2010. Les TIC en langues nationals. http://www.alfanet.anafa.org/ (accessed 25 August 2010).

Barry, T. M. 2010. Pulaar (fulfulde) sur la toile: www.peeral.com. Guinee Presse Info. http://www.guineepresse.info/index.php?id=3,5953,0,0,1,0 (accessed 23 August 2010).

Bourdieu, P. 1977. The economics of linguistic exchanges. Social Science Information 16. 651-653.

Bourdieu, P. \& L. J. D. Wacquant. 1992. An invitation to reflexive sociology. Cambridge: Polity.

von Braun, J. 2010. ICT for the poor at large scale: innovative connections to markets and services. In A. Picot \& J. Lorenz (eds.), ICT for the next five billion people: information and communication for sustainable development, 3-14. Berlin: Springer.

Cecchini, S. \& C. Scott. 2003. Can information and communications technology applications contribute to poverty reduction? Lessons from rural India. Information Technology for Development 10(2). 73-84.

Chigona, W., D. Beukes, J. Vally \& M. Tanner. 2009. Can mobile internet help alleviate social exclusion in developing countries? The Electronic Journal on Information Systems in Developing Countries 36(7). 1-16.

Coulibaly, P. B. 2001. Des radios à l'Internet : le rôle des technologies de l'information en tant qu'outils de transparence et de décentralisation du savoir. In A. Chéneau- Loquay (ed.), Enjeux des technologies de la communication en Afrique. Du téléphone à Internet, 1-8. Paris: Karthala-Regards.

Dia, I. A. 2001. Les enjeux sociopolitiques des nouvelles technologies de l'information et de la communication. Actes du colloque « Francophonie au pluriel » 10-20 mai. http://www.ulaval.ca/afi/colloques/colloque2001/actes/textes/dia.htm (accessed 2 September 2010).

Dia, I. A. 2009. Skilled international migration, information technology communication (ICTs) and the development of the country of origin: understanding the multiple meanings of the ICTs in the context of globalization, migrations and localities. Presentation during the International Workshop "ICT and Migrations: Mobility and Cohesion in the Digital Age", ICMPD, 24-25 September, Vienna, Austria.

Diki-Kidiri, Marcel. 2004. Multilinguisme et politiques linguistiques en Afrique. Colloque « Développement durable : leçons et perspectives » 1-4 June. http://www.francophoniedurable.org/documents/colloque-ouaga-a1-diki-kidiri.pdf (accessed 1 October 2013).

Djité, P. G. 2008. The sociolinguistics of development in Africa. Clevedon: Multilingual Matters.

Edelman, M. \& A. Haugerud (eds.). 2004. The anthropology of development and globalization: from classical political economy to contemporary neoliberalism (Blackwell Anthologies in Social and Cultural Anthropology). Oxford: Blackwell.

Ela, J. M. 1998. Refus du Développement ou Echec de l’Occidentalisation? Les voies de l'afro-renaissance. Monde diplomatique October.

Guignard, Thomas. 2008. Le Sénégal, les Sénégalais et l'Internet. Médias et identité. Lille : Université Charles De Gaulle doctoral thesis.

Harris, Roger. 2004. Information communication technologies for poverty alleviation. UNDPAPDIP, Malaysia.

Joseph, M. K. \& T. N. Andrew. 2007. Convergence opportunities and factors influencing the use of internet and telephony by rural women in South Africa and India: towards empowerment. In A. Venkatesh, T. Gonsalves, A. Monk \& K. Buckner (eds.), Home 
informatics and telematics: ICT for the next billion (International Federation for Information Processing 241), 1-20. Boston: Springer.

Kalusopa, T. 2005. The challenges of utilizing information communication technologies (ICTs) for the small-scale farmers in Zambia. Library Hi Tech 23(3). 414-424.

Lallana, E. C. \& M. N. Uy. 2003. The Information Age. Study for: The e-ASEAN Task Force and the UNDP Asia Pacific Development Information Programme (UNDP-APDIP).

Maumbe, B. M. \& J. Okello. 2010. Uses of information and communication technology (ICT) in agriculture and rural development in Sub-Saharan Africa: experiences from South Africa and Kenya. International Journal of ICT Research and Development in Africa 1(1). 1-22.

Mbembe, A. 1992. Provisonial note on the postcolony. Africa 62(1). 3-37.

Mufwene, S. 2002. Colonisation, globalisation, and the future of languages in the twenty-first century. International Journal on Multicultural Societies 4(2). 162-193.

Munyua, H. 2008. ICTs and small-scale agriculture in Africa: a scoping study. Final report. Published by the International Development Research Centre (IDRC).

Mutonyi, H. \& B. Norton. 2007. ICT on the margins: Lessons for Ugandan education. Language and Education 21(3). 264-270.

Ndangam, L. N. 2008. Free lunch? Cameroon's diaspora and online news publishing. New Media \& Society 10(4). 585-604.

Nkolola, W. M. 2010. The discourse of "call boys" and minibus conductors in Zambia: a hybrid sociolect of identity. Journal of Multicultural Discourses 5(2). 131-156.

Norris, Pippa. 2001. Digital divide: civic engagement, information poverty, and the internet worldwide (Communication, Society and Politics). New York: Cambridge University Press.

Omoniyi, T. 2003. Local policies, global forces: Multiliteracy through Africa's indigenous languages. Language Policy 2. 133-152.

Omoniyi, T. 2007. Alternative contexts of language policy and planning in Sub-Saharan Africa. TESOL Quarterly 41(3). 533-549.

Osborn, Donald Z. 2006. African languages and information and communication technologies: literacy, access, and the future. In John Mugane, John P. Hutchison \& Dee A. Worman (eds.), Selected proceedings of the 35th Annual Conference on African Linguistics, 86-93. Somerville, MA: Cascadilla Proceedings.

Powell, M. 2001. Knowledge, culture and the internet in Africa: a challenge for political economists. Review of African Political Economy. 28(88). 241- 260.

Prah, K. K. 2010. Multilingualism in urban Africa: bane or blessing. Journal of Multicultural Discourses 5(2). 169-182.

Rashid, A., \& L. Elder. 2009. Mobile phones and development: Analysis of IDRC supported projects. The Electronic Journal of Information Systems in Developing Countries 36(2). http://www.ejisdc.org/ojs2/index.php/ejisdc/article/view/529 (accessed 1 October 2013).

Sagna, 0. 2001. Les technologies de l'information et de la communication et le développement social au Sénégal, un état des lieux. Geneva: United Nations Research Institute of Social Development.

Sall, El H. M. I. 2009. L'appropriation des technologies de l'information et de la communication par des acteurs ruraux et urbains: Le cas du Sénégal. Mémoire de Maîtrise en développement régional, Université du Québec à Rimouski, Canada.

Schuppan, T. 2009. E-government in developing countries: Experiences from sub-Saharan Africa. Government Information Quarterly 26. 118-127.

Sen, A. K. 1999. Development as rreedom. New York: Anchor Books. 
Sene, K. \& R. Thioune. 2003. The policy influence of projects financed by IDRC's Acacia program Information \& Communication Technologies for Development (Acacia): The case of Senegal. Acacia Policy Influence Study/Senegal Strategic Assessment. Ottawa, Canada: International Development Research Center.

Snyder, I. \& M. Prinsloo. 2007. Young people's engagement with digital literacies in marginal contexts in a globalised world. Language and Education 21(3). 171-179.

Szirmai, A. 2005. The dynamics of socio-economic development. An introduction. Cambridge: Cambridge University Press.

Tynes, R. 2007. Nation-building and the diaspora on Leonenet: a case of Sierra Leone in cyberspace. New Media \& Society 9(3). 497-518.

UNDP (United Nations Development Program). 1990. Human development report. New York: Oxford University Press.

UNECA (United Nations Economic Commission for Africa). 2007. Harnessing ICT, science and technology for development in Africa. ICT, Science and Technology Division (ISTD).

Van der Veken, Aneleen \& Gilles-Maurice de Schryver. 2003. Les langues africaines sur la Toile: étude des cas haoussa, somali, lingala et isixhosa. Le traitement informatique des langues africaines 23 novembre. 33-45. http://www.rifal.org/cahiers/rifal23/rifal23.pdf (accessed 1 October 2013).

World Bank.2010. ICT at a glance definitions and sources. http://econ.worldbank.org/WBSITE/ EXTERNAL/DATASTATISTICS/0, contentMDK:20460697 isCURL:Y menuPK:1192714 page PK:64133150 piPK:64133175 theSitePK:239419,00.html (accessed 13 November 2010).

Warschauer, M. 2001. Singapore's dilemma: control vs. autonomy in IT-led development. The Information Society 17(4). 305-311.

Warschauer, M. 2004. Technology and social inclusion: rethinking the digital divide. Cambridge: MIT Press.

Wasserman, H \& A. S. de Beer. 2004. E-governance and e-publicanism: preliminary perspectives on the role of the Internet in South African democratic process. Communicatio 309(1). 64-89.

\section{Webography}

www.acalan.org/eng/accueil/accueil.php (accessed on 24 August 2010). www.wolof-online.com/ (accessed 06 September 2010). www.peeral.com (accessed 06 September 2010). 